\title{
Área foliar de feijão-vagem (Phaseolus vulgaris L.) em função de dimensões foliares
}

\author{
Leaf area of snap bean (Phaseolus vulgaris L.) \\ according to leaf dimensions
}

\author{
Marcos Toebe ${ }^{1}$; Alberto Cargnelutti Filho ${ }^{2 *}$; Luis Henrique Loose ${ }^{1}$; \\ Arno Bernardo Heldwein ${ }^{2}$; Alencar Junior Zanon ${ }^{1}$
}

\begin{abstract}
Resumo
O objetivo deste trabalho foi comparar os métodos de discos foliares e de fotos digitais, utilizados para determinar a área foliar de feijão-vagem (Phaseolus vulgaris L.) de hábito de crescimento indeterminado, e modelar a área foliar completa (três folíolos) em função do comprimento, ou da largura e/ou do produto comprimento vezes largura do folíolo central, de diferentes tamanhos de folhas. O experimento foi conduzido na Universidade Federal de Santa Maria, sob estufa plástica. Aos 55 dias após a semeadura, foram coletadas 191 folhas e mensurado o comprimento máximo e a largura máxima do folíolo central, e calculado o produto comprimento vezes largura. Posteriormente, determinou-se a área foliar completa (folíolos esquerdo, central e direito), por meio dos métodos de fotos digitais e de discos foliares. Análises de regressão linear e de correlação foram utilizadas para comparar os métodos. Modelos quadrático, potência e linear da área foliar completa (três folíolos) em função do comprimento, ou da largura e/ou do produto comprimento vezes largura do folíolo central foram ajustados, e validados por diferentes indicadores. Em feijão-vagem, os métodos de discos foliares e fotos digitais são discordantes. O método de fotos digitais representa adequadamente todo o limbo foliar, independentemente das diferentes relações de massa por área existentes, e é apropriado para a determinação da área foliar. Os modelos quadrático ( $\left.\hat{Y}=-4,8376+1,8908 x+2,2027 x^{2}, R^{2}=0,9901\right)$ e de potência $\left(\hat{Y}=2,5806 x^{1,9565}, R^{2}=0,9883\right)$ em função da largura do folíolo central (x) são adequados para estimar a área foliar completa (três folíolos) $(\hat{Y})$, obtida por meio do método de fotos digitais.

Palavras-chave: Fotos digitais, discos foliares, modelagem, método não-destrutivo
\end{abstract}

\begin{abstract}
The aim of this work was to compare the methods of leaf discs and digital photos used to determine the leaf area of snap bean (Phaseolus vulgaris L.), with indeterminate growth habit, and model complete leaf area (three leaflets) according the length, or width and or the product of length width, for different sizes of leaves. An experiment was conducted in a greenhouse at University Federal of Santa Maria, in Rio Grande do Sul State, Brazil. For this, in 191 leaves, collected 55 days after sowing, it was measured the maximum length and maximum width of central leaflet, and calculated the product of length width. After was determined leaf area of complete leaves (left, central and right leaflets), by the methods of digital photos and leaf discs. Linear regression analysis and correlation were used to compare the methods. The quadratic, potency and linear models of the leaf area as a function of the length, or width, or product of length width were adjusted, and validated by different indicators. In snap beans, the leaf
\end{abstract}

\footnotetext{
${ }^{1}$ Engenheiros Agrônomos, Mestrando(s) do Programa de Pós-Graduação em Agronomia, Universidade Federal de Santa Maria, UFSM, Santa Maria, RS. E-mail: m.toebe@gmail.com; luisloose@yahoo.com.br; alencarzanon@yahoo.com.br

${ }^{2}$ Engenheiros Agrônomos, Profs. Drs. do Dept ${ }^{0}$ de Fitotecnia, Centro de Ciências Rurais, CCR, UFSM, Santa Maria, RS. E-mail: alberto.cargnelutti.filho@gmail.com; heldweinab@smail.ufsm.br

* Autor para correspondência
} 
disks and digital photos methods are discordant. The method digital photos adequately represent the leaf limb, regardless of different mass per area exist, and is appropriate for the determination of leaf area. Quadratic model $\left(\hat{\mathrm{Y}}=-4.8376+1.8908 \mathrm{x}+2.2027 \mathrm{x}^{2}, \mathrm{R}^{2}=0.9901\right)$ and potency model $(\hat{\mathrm{Y}}=2.5806$ $\mathrm{x}^{1.9565}, \mathrm{R}^{2}=0.9883$ ) based on the width of central leaflet $(\mathrm{x})$ are adequate to estimate complete leaf area (three leaflets), determined by digital photos.

Key words: Digital photos, leaf discs, modeling, non-destructive method

\section{Introdução}

O feijão-vagem (Phaseolus vulgaris L.) pertence à família do feijão comum, diferindo no produto final, que é destinado, geralmente, ao consumo de vagens imaturas (FILGUEIRA, 2000), com folhas compostas por três folíolos. Determinações da área foliar são essenciais para que se possa entender a relação existente entre o crescimento das plantas e o ambiente onde a mesma está situada (JESUS JÚNIOR et al., 2001). Para determinar a área foliar diretamente, geralmente todas as folhas da planta são coletadas, caracterizando o método como destrutivo e de elevada mão-de-obra, enquanto que os métodos indiretos e não-destrutivos permitem avaliações sucessivas em uma mesma planta e rapidez nas avaliações.

Modelos de estimativa de área foliar, com base em dimensões lineares de folhas (comprimento, largura e comprimento vezes largura), foram gerados em cafeeiro (TAVARES JÚNIOR et al., 2002), tomate e pepino (BLANCO; FOLEGATTI, 2003), meloeiro (LOPES et al., 2007), girassol (MALDANER et al., 2009) e crambe (TOEBE et al., 2010). Em feijão-vagem de crescimento determinado o modelo potência foi considerado adequado para estimar a área foliar dos três folíolos com base na largura máxima, apenas, do folíolo central (QUEIROGA et al., 2003). No entanto, estudo de modelos que relacionam medidas lineares (comprimento, largura ou comprimento vezes largura) do folíolo central com a área foliar dos três folíolos (esquerdo, central e direito) determinada por fotos digitais (método não-destrutivo) e por discos foliares (método destrutivo) em feijão-vagem de hábito de crescimento indeterminado não foi encontrado na literatura. O objetivo deste trabalho foi comparar os métodos de discos foliares e de fotos digitais, utilizados para determinar a área foliar de feijão-vagem (Phaseolus vulgaris L.) de hábito de crescimento indeterminado, e modelar a área foliar completa (três folíolos) em função do comprimento, ou da largura e/ou do produto comprimento vezes largura do folíolo central, de diferentes tamanhos de folhas.

\section{Material e Métodos}

Foi conduzido um experimento com feijãovagem (Phaseolus vulgaris L.) cultivar "Macarrão", de crescimento indeterminado, na área experimental do Departamento de Fitotecnia, da Universidade Federal de Santa Maria, Santa Maria, Estado do Rio Grande do Sul, a $29^{\circ} 42^{\prime} \mathrm{S}, 53^{\circ} 49^{\prime} \mathrm{W}$, e a $95 \mathrm{~m}$ de altitude. $\mathrm{O}$ experimento foi conduzido no interior de uma estufa plástica, com cobertura de polietileno transparente de baixa densidade (PEBD) com $100 \mu \mathrm{m}$ de espessura, com $18 \mathrm{~m}$ de comprimento (direção norte-sul), $10 \mathrm{~m}$ de largura, $3 \mathrm{~m}$ de altura na parte central e $2 \mathrm{~m}$ de pé direito. A semeadura foi realizada em 23 de março de 2009, mantendo-se o espaçamento entre plantas de $0,20 \mathrm{~m}$ e entre linhas de 1,00 m. A área útil foi composta por 8 linhas com $16 \mathrm{~m}$ de comprimento totalizando 640 plantas.

Para a determinação da área foliar foram coletadas 191 folhas completas (cada folha composta pelos folíolos esquerdo, central e direito) aleatoriamente, com diferentes tamanhos, quando as plantas estavam em início de florescimento (55 dias após a semeadura). Nessas 191 folhas completas foi medido o comprimento (C) e a largura (L) máximos do folíolo central (Figura 1A), com régua milimetrada, e calculado o produto comprimento vezes largura $(\mathrm{C} \times \mathrm{L})$. Logo após, os três folíolos dessas mesmas folhas foram fotografados por meio 
de uma câmera digital da marca Sony, modelo DSC-W110. Após essas imagens foram processadas com o programa Sigma Scan Pro v. 5.0, Jandel Scientific (JANDEL SCIENTIFIC, 1991), para a determinação da área foliar por meio do método de fotos digitais. A seguir, nos três folíolos dessas mesmas folhas, foram extraídas áreas circulares (discos) de 2,34 cm de diâmetro, com auxílio de um calador. Obteve-se o número máximo possível de discos do limbo, incluindo as nervuras. Após, essas áreas circulares e o restante dos três folíolos foram secados em estufa até massa constante e pesados. Assim, com base no peso de uma área conhecida e no peso total dos três folíolos foi calculada a área foliar por meio do método de discos foliares, que nesse estudo foi considerado como método padrão, por sua ampla utilização em pesquisas dessa área. Assim, por meio desses dois métodos obteve-se a área foliar de cada folha completa pela soma das áreas dos três folíolos.

Figura 1. (A) Comprimento e largura máxima do folíolo central, utilizados para a construção de modelos de estimativa de aréa foliar das folhas completas (folíolo esquerdo, central e direito) de feijão-vagem (Phaseolus vulgaris L.). (B) Ajuste da regressão linear simples entre a área foliar determinada por fotos digitais e área foliar determinada por discos foliares de 191 folhas de feijão-vagem.

A

B
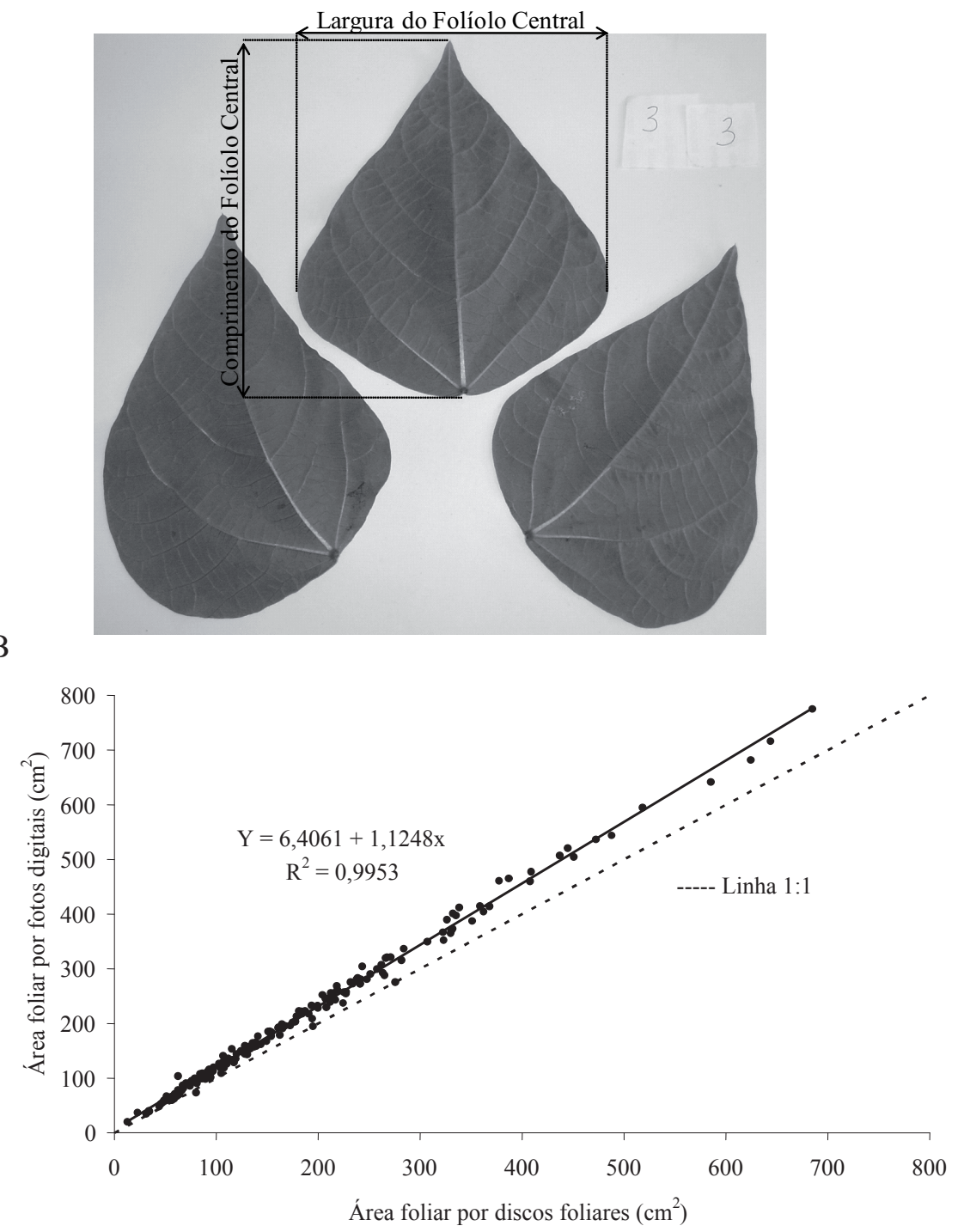

Fonte: Elaboração dos autores. 
Em relação ao comprimento (C), à largura (L), ao produto comprimento vezes largura $(\mathrm{C} \times \mathrm{L})$, às áreas foliares determinadas por meio de fotos digitais e de discos foliares, foram calculadas medidas de tendência central, de variabilidade, de assimetria e curtose e verificada a normalidade, por meio do teste de Lilliefors (CAMPOS, 1983).

A fim de avaliar a concordância entre os dois métodos, foi ajustada uma regressão linear simples (Y=a + bx) (DRAPER; SMITH, 1998) da área foliar determinada por meio de fotos digitais (variável dependente, nesse etapa do estudo considerada como uma variável aleatória) em função da área foliar determinada por meio de discos foliares (variável independente, nesse etapa do estudo considerada como uma variável fixa, por ser este o método padrão). Foram testadas as hipóteses $\mathrm{H}_{0}$ : a $=0$ versus $\mathrm{H}_{1}: \mathrm{a} \neq 0$ e $\mathrm{H}_{0}: \mathrm{b}=1$ versus $\mathrm{H}_{1}: \mathrm{b} \neq 1$, por meio do teste t de Student a 5\% de probabilidade de erro. A seguir foram calculados os coeficientes de correlação linear de Pearson (r) e de determinação $\left(\mathrm{R}^{2}\right)$ entre as áreas foliares determinadas por fotos digitais e discos foliares. A significância do $r$ foi avaliada por meio do teste t de Student a $5 \%$ de probabilidade de erro.

Após isso, nos dois métodos (fotos digitais e discos foliares), modelou-se a área foliar completa (Y) em função do $\mathrm{C}$, ou da $\mathrm{L}$ e/ou do $\mathrm{C} \times \mathrm{L}$, apenas, do folíolo central, por meio dos modelos: quadrático $\left(\mathrm{Y}=\mathrm{a}+\mathrm{bx}+\mathrm{cx}^{2}\right)$, potência $\left(\mathrm{Y}=\mathrm{ax} \mathrm{x}^{\mathrm{b}}\right)$ e linear $(\mathrm{Y}$ $=\mathrm{a}+\mathrm{bx})$, totalizando 18 modelos $(2$ métodos $\mathrm{x} 3$ modelos x 3 variáveis independentes), com auxílio do aplicativo Microsoft Office Excel, utilizando 10 casas decimais para o ajuste das equações.

A validação dos 18 modelos de estimativa de área foliar foi realizada com base nos 191 valores estimados pelo modelo $\left(\hat{Y}_{\mathrm{i}}\right)$ e os 191 valores observados $\left(\mathrm{Y}_{\mathrm{i}}\right)$. Em cada modelo, inicialmente, foi ajustada uma regressão linear simples ( $\hat{Y}_{i}$ $\left.=\mathrm{a}+\mathrm{bY}_{\mathrm{i}}\right)$ da área foliar estimada pelo modelo (variável dependente) em função da área foliar observada (variável independente). Foram testadas as hipóteses $\mathrm{H}_{0}: \mathrm{a}=0$ versus $\mathrm{H}_{1}: \mathrm{a} \neq 0$ e $\mathrm{H}_{0}: \mathrm{b}=$ 1 versus $\mathrm{H}_{1}: \mathrm{b} \neq 1$, por meio do teste $\mathrm{t}$ de Student a 5\% de probabilidade de erro. Em seguida foram calculados os coeficientes de correlação linear de Pearson (r) e de determinação $\left(R^{2}\right)$ entre $\hat{Y}_{i}$ e $Y_{i}$. A significância do $r$ foi avaliada por meio do teste t de Student a 5\% de probabilidade de erro. Para cada modelo, também foi calculado o erro absoluto médio (EAM), a raiz do quadrado médio do erro (RQME) e o índice d de Willmott (WILLMOTT, 1981), por meio, respectivamente, das expressões

$$
\begin{gathered}
E A M=\frac{\sum_{i=1}^{n}\left|\hat{Y}_{i}-Y_{i}\right|}{n}, \\
R Q M E=\sqrt{\frac{\sum_{i=1}^{n}\left(\hat{Y}_{i}-Y_{i}\right)^{2}}{n} e} \\
d=1-\left[\frac{\sum_{i=1}^{n}\left(\hat{Y}_{i}-Y_{i}\right)^{2}}{\sum_{i=1}^{n}\left(\left|\hat{Y}_{i}-\bar{Y}\right|+\left|Y_{i}-\bar{Y}\right|\right)^{2}}\right],
\end{gathered}
$$

em que $\hat{Y}_{i}$ são os valores estimados de área foliar, $Y_{i}$ são os valores observados de área foliar, $\bar{Y}$ é a média dos valores observados e $\mathrm{n}$ é o número de folhas $(n=191)$. Após obteve-se o índice CS de Camargo e Sentelhas (1997) pelo produto entre $\mathrm{r}$ e $\mathrm{d}(\mathrm{CS}=\mathrm{r} \times \mathrm{d})$.

O critério utilizado para a seleção dos modelos que melhor estimam a área foliar de feijão-vagem em função do $\mathrm{C}$, ou da L e/ou do $\mathrm{C} \times \mathrm{L}$ foi: coeficiente linear (a) não diferente de zero, coeficiente angular (b) não diferente de um, coeficientes de correlação linear de Pearson ( $\mathrm{r}$ ) e de determinação $\left(\mathrm{R}^{2}\right)$ mais próximos de um, erro absoluto médio (EAM) e raiz do quadrado médio do erro (RQME) mais próximo de zero, e índices d de Willmott (WILLMOTT, 1981) e CS de Camargo e Sentelhas (1997) mais próximos de um. 


\section{Resultados e Discussão}

As medidas de tendência central, de variabilidade, de assimetria e curtose, em relação ao comprimento $(\mathrm{C})$, à largura $(\mathrm{L})$, ao produto comprimento vezes largura $(\mathrm{C} \times \mathrm{L})$, às áreas foliares determinadas por meio de fotos digitais e de discos foliares, revelam que os dados das 191 folhas não se ajustaram a distribuição normal $(\mathrm{p} \leq 0,05)$ (Tabela 1). A maior magnitude da média em relação à mediana e a assimetria positiva $(\mathrm{p} \leq 0,05)$ indicam maior frequência de folhas com valores próximos ao mínimo e uma menor frequência de valores próximos ao máximo (Figura 1B), confirmando a não normalidade dos dados. A variabilidade existente é importante e confere adequabilidade desses dados para geração de modelos. A média de área foliar determinada por fotos digitais e por discos foliares, das 191 folhas foi, respectivamente, 204,7454 e $176,3268 \mathrm{~cm}^{2}$ (Tabela 1). Esses resultados indicam que a área foliar determinada por meio do método de fotos digitais é $16 \%$ maior que a determinada por discos foliares.

Tabela 1. Mínimo, máximo, média, mediana, desvio-padrão, coeficiente de variação (CV), assimetria, curtose e teste de Lilliefors do comprimento do folíolo central (C), da largura do folíolo central (L), do produto comprimento vezes largura $(\mathrm{C} \times \mathrm{L})$, da área foliar determinada por fotos digitais (AFFD) e da área foliar determinada por discos foliares (AFDF) de 191 folhas de feijão-vagem (Phaseolus vulgaris L.).

\begin{tabular}{llllll}
\hline Estatística & Comprimento $(\mathrm{cm})$ & Largura $(\mathrm{cm})$ & $\mathrm{C} \times \mathrm{L}\left(\mathrm{cm}^{2}\right)$ & AFFD $\left(\mathrm{cm}^{2}\right)$ & AFDF $\left(\mathrm{cm}^{2}\right)$ \\
\hline Mínimo & 3,8000 & 2,8000 & 11,7600 & 20,5342 & 12,4957 \\
Máximo & 20,3000 & 18,4000 & 371,6800 & 775,6342 & 684,8540 \\
Média & 10,6440 & 8,8618 & 103,7113 & 204,7454 & 176,3268 \\
Mediana & 10,3000 & 8,4000 & 85,8600 & 159,4554 & 137,0737 \\
Desvio-padrão & 3,2094 & 3,0099 & 67,8744 & 140,4236 & 124,5457 \\
$\mathrm{CV}(\%)$ & 30,1520 & 33,9650 & 65,4455 & 68,5845 & 70,6334 \\
Assimetria ${ }^{(1)}$ & $0,6641 *$ & $0,7135 *$ & $1,4956 *$ & $1,4850 *$ & $1,5607 *$ \\
Curtose $+3^{(2)}$ & $3,3963 \mathrm{~ns}$ & $3,2512 \mathrm{~ns}$ & $5,5584 *$ & $5,4493 *$ & $5,8193 *$ \\
Lilliefors $^{(3)}$ & $0,0759 *$ & $0,1038^{*}$ & $0,1135 *$ & $0,1291 *$ & $0,1309 *$ \\
\hline
\end{tabular}

(1) * Assimetria difere de zero, pelo teste t, em nível de 5\% de probabilidade. ns = Não-significativo.

(2) * Curtose difere de três, pelo teste t, em nível de 5\% de probabilidade. ns = Não-significativo.

(3) * Significativo a de $5 \%$ de probabilidade. ns = Não-significativo.

Fonte: Elaboração dos autores.

Os coeficientes linear (a) e angular (b), da regressão linear simples, da área foliar determinada por meio de fotos digitais (variável dependente) em função da área foliar determinada por meio de discos foliares (variável independente) foram, respectivamente, maiores que zero $(\mathrm{a}=6,4061, \mathrm{p} \leq$ $0,05)$ e um $(b=1,1248, p \leq 0,05)$. Esses resultados revelam que há superioridade $(\mathrm{a}=6,4061)$ das áreas foliares determinadas por fotos digitais em relação às determinadas por discos foliares. Além disso, há tendência crescente $(b=1,1248)$, ou seja, quanto maiores forem as folhas, maiores serão as diferenças entre as áreas foliares determinadas por meio dos dois métodos (Figura 1B), no entanto o percentual médio de $16 \%$ manteve-se constante. Ainda, o modelo $\hat{Y}=6,4061+1,1248 x$ (Figura 1B) representa que para cada aumento de uma unidade na área foliar determinada por discos foliares, a área foliar determinada por fotos digitais aumenta, em média, 1,1248 unidades. Então, pode-se inferir que os métodos fornecem áreas foliares distintas, pois os coeficientes de correlação linear de Pearson ( $\mathrm{r}=$ $0,9976, p \leq 0,05)$ e de determinação $\left(R^{2}=0,9953\right)$, embora elevados, devem ser vistos com cautela, pelo fato de apenas evidenciarem que há relação linear entre as variáveis. Lopes et al. (2007) encontraram 
coeficiente de correlação linear elevado $(r=0,99)$ na cultura de meloeiro, entre a área foliar determinada por meio dos métodos de fotos digitais e de discos foliares, sem, contudo, avaliar os coeficientes linear (a) e angular (b).

Embora o método de discos foliares seja amplamente utilizado em distintas culturas agrícolas (TAVARES JÚNIOR et al., 2002; LOPES et al., 2007; MALDANER et al., 2009; TOEBE et al., 2010), particularmente, na determinação da área foliar de feijão-vagem, nesse estudo, revelouse como inadequado, por subestimar a área foliar (Figura 1B). Isso se deve ao fato da diferença entre a relação da massa por área das nervuras centrais dos folíolos quando comparada à relação massa por área do restante dos folíolos. Por sua vez o método de fotos digitais representa adequadamente todo o limbo foliar, independentemente das diferentes relações de massa por área existentes. Então, podese inferir que em feijão-vagem o método de fotos digitais é adequado para a determinação da área foliar. Esses resultados corroboram com Tavares Júnior et al. (2002) que recomendaram o uso do método de fotos digitais por sua maior exatidão em relação ao método de discos foliares.

De maneira geral, os modelos (quadrático, potência e linear) que relacionam a área foliar determinada pormeio de fotos digitais e a determinada por meio de discos foliares, das folhas completas (três folíolos), com o comprimento, ou com a largura e/ou com o produto comprimento vezes largura, do folíolo central, apresentaram ajustes semelhantes (Tabela 2). Os elevados valores do coeficiente de determinação $\left(\mathrm{R}^{2} \geq 0,9153\right)$ sugerem que todos os modelos poderiam ser utilizados para estimar a área foliar. Também, pode-se inferir que, a inclusão das mensurações dos folíolos esquerdo e direito, como variáveis independentes, não forneceriam acréscimo substancial na precisão dos modelos, que justificasse a mão-de-obra acrescentada para as suas mensurações.
Nos dois métodos (fotos digitais e discos foliares), os modelos quadráticos e de potência ajustados em função da largura apresentaram desempenhos superiores (maiores valores de $\mathrm{R}^{2}$ ) aos ajustados em função do comprimento. Em relação às culturas de tomate e pepino (BLANCO; FOLEGATTI, 2003), de meloeiro (LOPES et al., 2007) e de crambe (TOEBE et al., 2010) foram encontrados resultados semelhantes, com menores valores de coeficiente de determinação quando utilizaram a variável comprimento para determinação da área foliar determinada por fotos digitais ou por discos foliares. Já os modelos ajustados em função do produto comprimento vezes largura ficaram em situação intermediária, porém similares àqueles que consideraram somente a largura, indicando que essa variável independente não melhora o ajuste dos modelos. Assim, em função da maior mãode-obra necessária para a coleta de duas variáveis (comprimento e largura) para a determinação do $\mathrm{C} \times \mathrm{L}$, não se justifica a utilização destas equações, e sim, a utilização das equações que consideram apenas a variável largura, pela praticidade e precisão dos resultados (Tabela 2).

Nos modelos lineares, os melhores ajustes foram obtidos em função do produto comprimento largura. Por sua simplicidade o modelo linear poderia ser o preferido. No entanto, para ter o desempenho semelhante aos modelos quadráticos e de potência, ajustados em função da largura, necessitaria das duas medidas (comprimento e largura). Assim, pode-se inferir que os modelos quadráticos e de potência com base na largura são os mais adequados, concordando com Queiroga et al. (2003), Maldaner et al. (2009) e Toebe et al. (2010), que concluíram que os modelos do tipo potência e quadrático utilizando a largura da folha, são os mais precisos e adequados para estimar a área foliar de feijão-vagem de hábito de crescimento determinado, girassol e crambe, respectivamente, independentemente do tamanho das folhas. 
Tabela 2. Equações para a determinação da área foliar (Y) por discos foliares e por fotos digitais, utilizando o comprimento $(\mathrm{C})$, a largura $(\mathrm{L})$ e o produto comprimento vezes largura $(\mathrm{C} \times \mathrm{L})$ como variáveis independentes $(\mathrm{x}) \mathrm{e}$ coeficiente de determinação, em feijão-vagem (Phaseolus vulgaris L.).

\begin{tabular}{|c|c|c|c|}
\hline Modelo & $\begin{array}{c}\text { Variável } \\
\text { independente }(\mathrm{x})\end{array}$ & Equação & $\begin{array}{l}\text { Coeficiente de } \\
\text { determinação }\end{array}$ \\
\hline \multicolumn{4}{|c|}{---- Área foliar determinada por fotos digitais em função de C, L e C×L } \\
\hline 1) Quadrático & $\mathrm{C}$ & $\hat{\mathrm{Y}}=4,3420-3,9217 \mathrm{x}+1,9601 \mathrm{x}^{2}$ & 0,9581 \\
\hline 2) Quadrático & $\mathrm{L}$ & $\hat{Y}=-4,8376+1,8908 x+2,2027 x^{2}$ & 0,9901 \\
\hline 3) Quadrático & $\mathrm{C} \times \mathrm{L}$ & $\hat{Y}=-8,5152+2,0583 x-0,00001 x^{2}$ & 0,9857 \\
\hline 4) Potência & $\mathrm{C}$ & $\hat{Y}=1,1473 x^{2,1416}$ & 0,9484 \\
\hline 5) Potência & $\mathrm{L}$ & $\hat{\mathrm{Y}}=2,5806 \mathrm{x}^{1,9565}$ & 0,9883 \\
\hline 6) Potência & $\mathrm{C} \times \mathrm{L}$ & $\hat{Y}=1,6544 x^{1,0354}$ & 0,9815 \\
\hline 7) Linear & $\mathrm{C}$ & $\hat{Y}=-241,6378+41,9376 x$ & 0,9186 \\
\hline 8) Linear & $\mathrm{L}$ & $\hat{Y}=-199,4471+45,6108 x$ & 0,9557 \\
\hline 9) Linear & $\mathrm{C} \times \mathrm{L}$ & $\hat{\mathrm{Y}}=-8,2901+2,0541 \mathrm{x}$ & 0,9857 \\
\hline \multicolumn{4}{|c|}{------- Área foliar determinada por discos foliares em função de $\mathrm{C}, \mathrm{L}$ e $\mathrm{C} \times \mathrm{L}$} \\
\hline 10) Quadrático & $\mathrm{C}$ & $\hat{Y}=14,7828-6,4317 x+1,8618 x^{2}$ & 0,9606 \\
\hline 11) Quadrático & $\mathrm{L}$ & $\hat{Y}=5,0745-1,4843 x+2,1065 x^{2}$ & 0,9897 \\
\hline 12) Quadrático & $\mathrm{C} \times \mathrm{L}$ & $\hat{Y}=-7,6673+1,7294 x+0,0003 x^{2}$ & 0,9867 \\
\hline 13) Potência & $\mathrm{C}$ & $\hat{Y}=0,8323 x^{2,2104}$ & 0,9484 \\
\hline 14) Potência & $\mathrm{L}$ & $\hat{\mathrm{Y}}=1,9285 \mathrm{x}^{2,0177}$ & 0,9866 \\
\hline 15) Potência & $\mathrm{C} \times \mathrm{L}$ & $\hat{\mathrm{Y}}=1,2169 \mathrm{x}^{1,0682}$ & 0,9806 \\
\hline 16) Linear & $\mathrm{C}$ & $\hat{Y}=-218,8612+37,1278 x$ & 0,9153 \\
\hline 17) Linear & $\mathrm{L}$ & $\hat{Y}=-181,0357+40,3263 x$ & 0,9497 \\
\hline 18) Linear & $\mathrm{C} \times \mathrm{L}$ & $\hat{Y}=-12,6840+1,8225 x$ & 0,9864 \\
\hline
\end{tabular}

Fonte: Elaboração dos autores.

Os indicadores utilizados para avaliar o desempenho dos modelos de estimativa da área foliar de feijão-vagem em função do comprimento, ou da largura e/ou do produto comprimento vezes largura (Tabela 3) corroboram os resultados discutidos anteriormente. Portanto, confirma-se a inferência de que os modelos quadráticos e de potência com base na largura são os mais adequados e podem ser utilizados para estimativa da área foliar.

Do ponto de vista prático, a adequação do método de fotos digitais para a determinação da área foliar de feijão-vagem e os elevados ajustes das equações quadrática $\left(\hat{\mathrm{Y}}=-4,8376+1,8908 \mathrm{x}+2,2027 \mathrm{x}^{2}\right.$, $\left.\mathrm{R}^{2}=0,9901\right)$ e de potência $\left(\hat{\mathrm{Y}}=2,5806 \mathrm{x}^{1,9565}, \mathrm{R}^{2}\right.$ $=0,9883$ ) evidenciam que a medição da largura do folíolo central (x) é suficiente para estimar a área foliar dos três folíolos ( $\hat{Y}$ ) (FIGURAS 2Ae 2B). Esse resultado é importante, pois permite a estimativa da área foliar sem necessidade de destruir as folhas e com base em uma medida (largura) de apenas um folíolo (central) e ainda com elevada precisão. 
Tabela 3. Coeficientes linear (a), angular (b), de correlação linear de Pearson (r) e de determinação ( $\mathrm{R}^{2}$ ) obtidos na regressão linear ajustada entre a área foliar estimada (variável dependente) e a observada (variável independente). Erro absoluto médio (EAM), raiz do quadrado médio do erro (RQME), índice d de Willmott (WILLMOTT, 1981) e índice CS de Camargo e Sentelhas (1997) calculados com base na área foliar estimada e observada, de 191 folhas de feijão-vagem (Phaseolus vulgaris L.), por meio de diferentes modelos.

\begin{tabular}{lllllllll}
\hline Modelo $^{(1)}$ & $\mathrm{a}^{(2)}$ & $\mathrm{b}^{(3)}$ & $\mathrm{r}^{(4)}$ & $\mathrm{R}^{2}$ & EAM & RQME & $\mathrm{d}$ & CS \\
\hline 1 & $8,5632 *$ & $0,9581 *$ & $0,9788 *$ & 0,9581 & 20,3491 & 28,6425 & 0,9892 & 0,9683 \\
2 & $2,0103 \mathrm{~ns}$ & $0,9901 \mathrm{~ns}$ & $0,9950 *$ & 0,9901 & 9,8884 & 13,8779 & 0,9975 & 0,9926 \\
3 & $2,9097 \mathrm{~ns}$ & $0,9857 \mathrm{~ns}$ & $0,9928 *$ & 0,9857 & 11,9754 & 16,6962 & 0,9964 & 0,9893 \\
4 & $9,9713 *$ & $0,9375 *$ & $0,9787 *$ & 0,9579 & 20,3449 & 28,9900 & 0,9887 & 0,9677 \\
5 & $2,8555 \mathrm{~ns}$ & $0,9827 *$ & $0,9950 *$ & 0,9902 & 9,9775 & 13,9169 & 0,9974 & 0,9925 \\
6 & $3,3604 \mathrm{~ns}$ & $0,9781 *$ & $0,9928 *$ & 0,9856 & 11,8669 & 16,8336 & 0,9963 & 0,9891 \\
7 & $16,6487 *$ & $0,9186 *$ & $0,9584 *$ & 0,9186 & 30,9544 & 39,9377 & 0,9784 & 0,9377 \\
8 & $9,0528 *$ & $0,9557 *$ & $0,9776 *$ & 0,9557 & 21,1590 & 29,4501 & 0,9885 & 0,9664 \\
9 & $2,9098 \mathrm{~ns}$ & $0,9857 \mathrm{~ns}$ & $0,9928 *$ & 0,9857 & 11,9663 & 16,6965 & 0,9964 & 0,9893 \\
10 & $6,9417 *$ & $0,9606 *$ & $0,9801 *$ & 0,9606 & 17,8598 & 24,6470 & 0,9898 & 0,9701 \\
11 & $1,8032 \mathrm{~ns}$ & $0,9897 \mathrm{~ns}$ & $0,9948 *$ & 0,9897 & 8,9679 & 12,5617 & 0,9974 & 0,9923 \\
12 & $2,3394 \mathrm{~ns}$ & $0,9867 \mathrm{~ns}$ & $0,9933 *$ & 0,9867 & 10,5570 & 14,3081 & 0,9966 & 0,9900 \\
13 & $7,5490 *$ & $0,9443 *$ & $0,9800 *$ & 0,9605 & 17,8162 & 24,8712 & 0,9895 & 0,9697 \\
14 & $1,9210 \mathrm{~ns}$ & $0,9869 \mathrm{~ns}$ & $0,9948 *$ & 0,9897 & 8,9316 & 12,5817 & 0,9974 & 0,9922 \\
15 & $2,0743 \mathrm{~ns}$ & $0,9840 \mathrm{~ns}$ & $0,9933 *$ & 0,9867 & 10,3593 & 14,3342 & 0,9966 & 0,9899 \\
16 & $14,9280 *$ & $0,9153 *$ & $0,9567 *$ & 0,9153 & 27,5177 & 36,1436 & 0,9774 & 0,9351 \\
17 & $8,8545 *$ & $0,9497 *$ & $0,9745 *$ & 0,9497 & 19,5948 & 27,8363 & 0,9869 & 0,9618 \\
18 & $2,3889 \mathrm{~ns}$ & $0,9864 \mathrm{~ns}$ & $0,9932 *$ & 0,9864 & 10,9592 & 14,4589 & 0,9965 & 0,9898 \\
\hline
\end{tabular}

(1) Modelos definidos na tabela 2.

(2) * Coeficiente linear difere de zero, pelo teste $\mathrm{t}$, em nível de $5 \%$ de probabilidade. $\mathrm{ns}=$ Não-significativo.

(3) * Coeficiente angular difere de um, pelo teste t, em nível de $5 \%$ de probabilidade. ns = Não-significativo.

(4) * Coeficiente de correlação difere de zero, pelo teste t, em nível de 5\% de probabilidade. ns = Não-significativo.

Fonte: Elaboração dos autores. 
Figura 2. Modelos quadrático (A) e potência (B) da área foliar completa (três folíolos) (Ŷ) de feijão-vagem (Phaseolus vulgaris L.), obtida por meio do método de fotos digitais, em função da largura máxima do folíolo central (x).

A

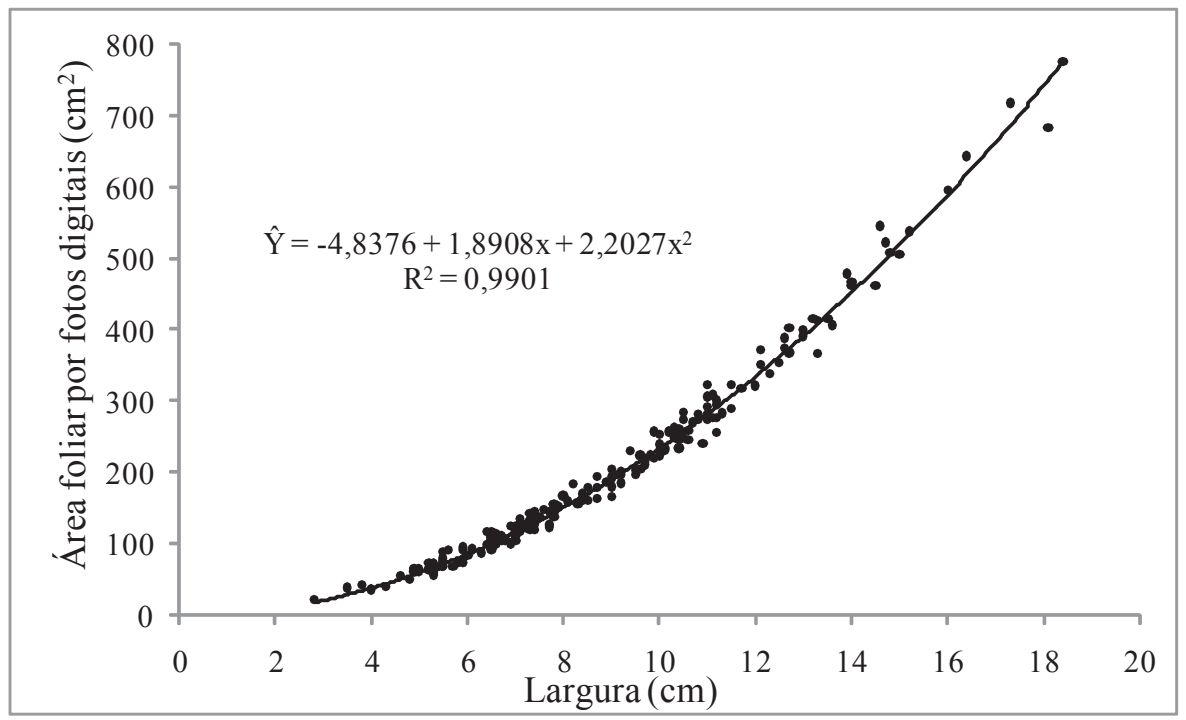

B

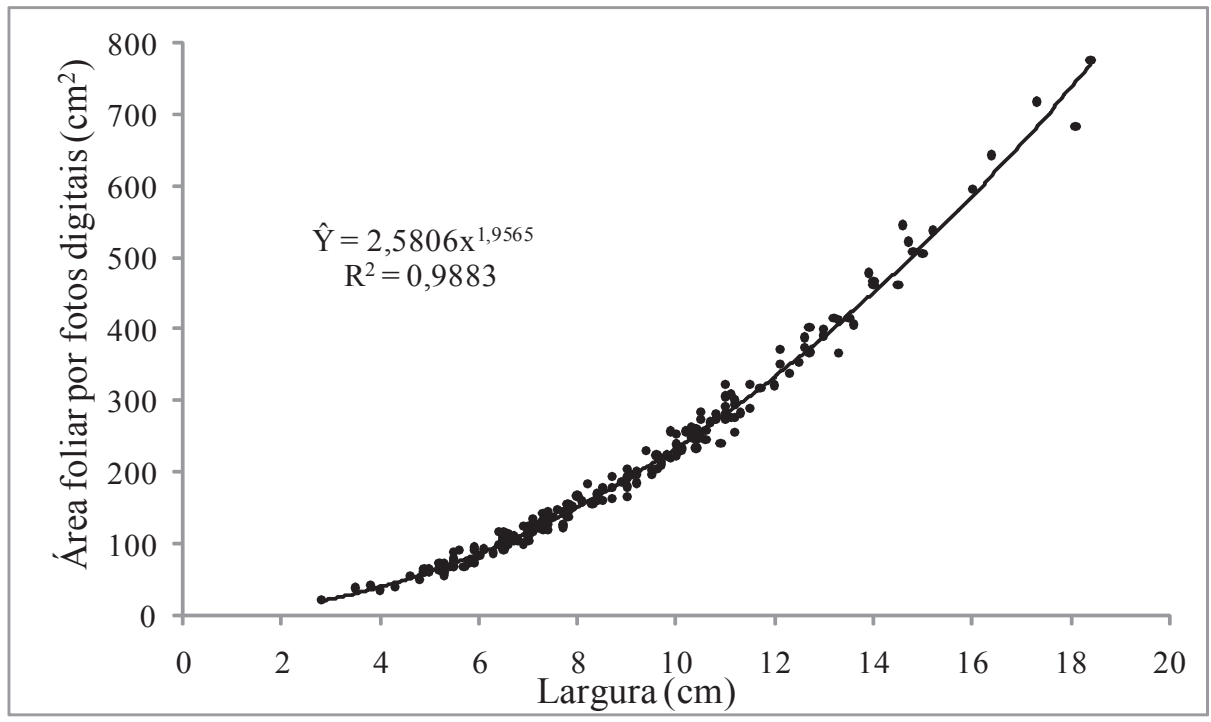

Fonte: Elaboração dos autores.

\section{Conclusões}

Em feijão-vagem (Phaseolus vulgaris L.) de hábito de crescimento indeterminado, os métodos de discos foliares e de fotos digitais são discordantes em relação à estimativa de área foliar. $\mathrm{O}$ método de fotos digitais representa adequadamente todo o limbo foliar, independentemente das diferentes relações de massa por área existentes, e é apropriado para a determinação da área foliar. Os modelos quadrático $\left(\hat{\mathrm{Y}}=-4,8376+1,8908 \mathrm{x}+2,2027 \mathrm{x}^{2}\right.$, $\left.\mathrm{R}^{2}=0,9901\right)$ e de potência $\left(\hat{\mathrm{Y}}=2,5806 \mathrm{x}^{1,9565}, \mathrm{R}^{2}=\right.$ $0,9883)$ em função da largura do folíolo central (x) são adequados para estimar a área foliar completa (três folíolos) (Ŷ), obtida por meio do método de fotos digitais. 


\section{Agradecimentos}

Ao Conselho Nacional de Desenvolvimento Científico e Tecnológico e à Coordenação de Aperfeiçoamento de Pessoal de Nível Superior pelas bolsas concedidas.

\section{Referências}

BLANCO, F. F.; FOLEGATTI, M. V. A new method for estimating the leaf area index of cucumber and tomato plants. Horticultura Brasileira, Brasília, v. 21, n. 4, p. 666-669, 2003.

CAMARGO, A. P. de; SEnTElhas, P. C. Avaliação do desempenho de diferentes métodos de estimativa da evapotranspiração potencial no estado de São Paulo, Brasil. Revista Brasileira de Agrometeorologia, Santa Maria, v. 5, n. 1, p. 89-97, 1997.

CAMPOS, H. de. Estatística experimental nãoparamétrica. 4. ed. Piracicaba: Departamento de Matemática e Estatística/ESALQ, 1983. 349 p.

DRAPER, N. R.; SMITH, H. A. Applied regression analysis. 3. ed. New York: Wiley, 1998. 736 p.

FILGUEIRA, F. A. R. Novo Manual de olericultura: agrotecnologia moderna na produção de hortaliças. Viçosa: UFV, 2000. 421 p.

JANDEL SCIENTIFIC. User's manual. Califórnia: Jandel Scientific, 1991. $280 \mathrm{p}$.
JESUS JÚNIOR, W. C.; VALE, F. X. R.; COELHO, R. R.; COSTA, L. C. Comparison of two methods for estimating leaf area index on common bean. Agronomy Journal, Madison, v. 93, n. 5, p. 989-991, 2001.

LOPES, S. J.; BRUM, B.; SANTOS, V. J.; FAGAN, E. B.; LUZ, G. L.; MEDEIROS, S. L. P. Estimativa da área foliar de meloeiro em diferentes estádios fenológicos por fotos digitais. Ciência Rural, Santa Maria, v. 37, n. 4, p. 1153-1156, 2007.

MALDANER, I. C.; HELDWEIN, A. B.; LOOSE, L. H.; LUCAS, D. D. P.; GUSE, F. I.; BORTOLUZZI, M.P. Modelos de determinação não-destrutiva da área foliar em girassol. Ciência Rural, Santa Maria, v. 39, n. 5, p. 1356-1361, 2009.

QUEIROGA, J. L.; ROMANO, E. D. U.; SOUZA, J. R. P.; MIGLIORANZA, E. Estimativa da área foliar do feijão-vagem (Phaseolus vulgaris L.) por meio da largura máxima do folíolo central. Horticultura Brasileira, Brasília, v. 21, n. 1, p. 64-68, 2003.

TAVARES JUNIOR, J. E.; FAVARIN, J. L.; DOURADO NETO, D.; MAIA, A. de H. N.; FAZUOLI, L. C.; BERNARDES, M. S. Análise comparativa de métodos de estimativa de área foliar em cafeeiro. Bragantia, Campinas, v. 61, n. 2, p. 199-203, 2002.

TOEBE, M.; BRUM, B.; LOPES, S. J.; CARGNELUTTI FILHO, A.; SILVEIRA, T. R. Estimativa da área foliar de Crambe abyssinica por discos foliares e por fotos digitais. Ciência Rural, Santa Maria, v. 40, n. 2, p. 445-448, 2010.

WILLMOTT, C. J. On the validation of models. Physical Geography, Los Angeles, v. 2, n. 2, p. 184-194, 1981. 